Proceedings of the XXIII Conference on Applied Crystallography, Krynica Zdrój, Poland, September 20-24, 2015

\title{
Semi-Conducting Properties of Titanium Dioxide Layer on Surface of Ti-15Mo Implant Alloy in Biological Milieu
}

\author{
M. Szklarska ${ }^{a}$, G. Dercz ${ }^{a}$, J. Kubisztal ${ }^{a}$, K. Balin ${ }^{b}$ And B. EosieWicz ${ }^{a, *}$ \\ ${ }^{a}$ Institute of Materials Science, University of Silesia, 75 Pułku Piechoty 1A, 41-500 Chorzów, Poland \\ ${ }^{b}$ A. Chełkowski Institute of Physics, University of Silesia, Uniwersytecka 4, 40-007 Katowice, Poland
}

\begin{abstract}
The object of this work was to investigate structure, electrochemical behavior and semiconducting properties of the $\mathrm{TiO}_{2}$ oxide layer on the $\mathrm{Ti}-15 \mathrm{Mo}$ implant alloy surface in normal and inflammatory conditions of physiological saline solution. X-ray photoelectron spectroscopy measurements confirm the presence of the oxide layer on the Ti$15 \mathrm{Mo}$ alloy surface. Electrochemical studies indicate excellent corrosion resistance of Ti-15Mo alloy in physiological saline solution. It was found that the investigated material under normal and inflammatory conditions behave like an insulator and $n$-type semiconductor, respectively.
\end{abstract}

DOI: 10.12693/APhysPolA.130.1085

PACS/topics: 87.85.jj, 82.45.Bb, 72.20.-i

\section{Introduction}

Titanium and its alloys with mechanical properties similar to the human bones, low weight and Young modules, high biocompatibility, biological inertness, and good corrosion resistance are excellent materials for biomedical applications [1-4]. Among these materials, a $\mathrm{Ti}^{-}$ $15 \mathrm{Mo}$ alloy can be distinguished. Addition of Mo increases the corrosion resistance simultaneously reducing the elastic modulus [4]. Moreover, because of the high oxygen affinity of $\mathrm{Ti}$ and its alloys, the $\mathrm{Ti}-15 \mathrm{Mo}$ alloy is self-passivated material and is covered with a stable oxide layer which is strongly adherent to the surface and protects it against harmful environmental factors, e.g. human body $[3,5]$. In many cases the implementation of dental or orthopaedic device provokes an inflammatory response of human body. During the inflammation the amount of hydrogen peroxide is growing, $\mathrm{pH}$ level is decreasing, and these changes can strongly affect corrosion behavior of the implants [6-8]. Therefore, the aim of this study is to examine structure, electrochemical behavior, and semiconducting properties of the oxide layer on the Ti-15Mo implant alloy in physiological saline solution (PSS) under normal and inflammatory conditions.

\section{Experimental}

Phase composition of the Ti-15Mo implant was tested by X-ray diffraction with the use of an X-ray X'Pert diffractometer manufactured by Phillips, with copper target X-ray tube $(\lambda=1.54 \AA)$ operated at $40 \mathrm{kV}$ and $30 \mathrm{~mA} . \mathrm{Cu} K_{\alpha}$ radiation was monochromatized with a graphite monochromizer. Wide angle X-ray scattering (WAXS) curves were recorded in a step scanning mode, over a diffraction angle $(2 \theta)$ range: $20^{\circ}-140^{\circ}$, with the step of $0.05^{\circ}$.

*corresponding author; e-mail: bozena. Łosiewicz@us.edu.pl
Chemical composition of thin oxide layer spontaneously formed on the Ti-15Mo surface has been studied towards X-ray photoelectron spectroscopy (XPS). The XPS measurements were realized with the use of VGScienta \& Prevac spectrometer. Monochromatized Al $K_{\alpha}$ radiation was used to obtain the photoelectron spectra of Mo $3 d$, Ti $2 p$, O $1 s$ and $\mathrm{C} 1 s$ before and after the sputtering process ( $\mathrm{Ar}^{+}$ions, $\left.9 \mathrm{~mA}, 4 \mathrm{kV}, 20 \mathrm{~min}\right)$. The electrochemical measurements were carried out in electrochemical cell described previously [3] in a PSS of $0.9 \% \mathrm{NaCl}$ solution of $\mathrm{pH}=7.4 \pm 0.1$ at $37 \pm 1^{\circ} \mathrm{C}$ and in PSS with $15 \mathrm{mM} \mathrm{H}_{2} \mathrm{O}_{2}$ solution of $\mathrm{pH}=4.5 \pm 0.1$ (titrated $\mathrm{HCl}$ ) at $40 \pm 1{ }^{\circ} \mathrm{C}$ to simulate normal and inflammatory physiological conditions in human body, respectively. Electrical properties of the oxide layer were analysed by anodic polarization and electrochemical impedance spectroscopy (EIS) methods using the Metrohm/Eco Chemie Autloab PGSTAT30 potentiostat/galvanostat electrochemical system. The $E_{O C}$ was stabilized for $2 \mathrm{~h}$. Based on the anodic polarization curves, the potential range from $+5 \mathrm{~V}$ to $-0.3 \mathrm{~V}$ vs. saturated calomel electrode (SCE) for EIS measurements was selected. Impedance spectra registered potentiostatically at frequencies of $50 \mathrm{kHz}-$ $0.1 \mathrm{~Hz}$ were approximated using the EQUIVCRT program. Scanning Kelvin probe (SKP) measurements were used to obtain the topography map of the sample and to determine the changes in the distribution of contact potential difference on the bottom of corrosion pit and surface of Ti-15Mo sample. The SKP tests were conducted using scanning electrochemical workstation M370.

\section{Results and discussion}

The X-ray analysis confirmed that the Ti15Mo implant alloy contained only $\beta$-Ti phase (ICDD PDF 01089-4913) which improves corrosion resistance and mechanical properties. Moreover, excellent corrosion resistance of the Ti-15Mo alloy is also provided by presence of stable, spontaneously formed on air, oxide layer on its 
surface. The XPS was used to determine the oxidation states of $\mathrm{Ti}$ and Mo on the surface of the $\mathrm{Ti}-15 \mathrm{Mo}$ alloy. The survey spectra obtained before and after the sputtering process showed principal core levels of Ti, Mo, O and $\mathrm{C}$ (the last one significantly removed during the sputtering process). The atomic concentration calculations before and after sputtering process indicate uniform ratio of $\mathrm{Ti} / \mathrm{Mo}$, which confirms homogenous distribution of $\mathrm{Ti}$ and Mo on subsurface layers of the alloy. The analysis of chemical states of $\mathrm{Ti}$ and Mo, obtained from detailed analysis of the Ti $2 p$ and Mo $3 d$ multiplets (Fig. 1), indicated that both elements, before and after sputtering process, exhibit metallic as well as oxide nature. The low binding energy states of Ti determined for Ti $2 p_{2 / 3}$ were at $454.58 \mathrm{eV}$ before the sputtering process and at $454.7 \mathrm{eV}$ after sputtering process. In case of low binding energy states of Mo, here given for Mo $3 d_{5 / 2}$ were obtained at $227.75 \mathrm{eV}$ before sputtering process and at $227.9 \mathrm{eV}$ after the sputtering process. Both results indicate presence of $\mathrm{Ti}$ and Mo in metallic state. Presence of metallic states of $\mathrm{Ti}$ and Mo before sputtering process indicates that the oxide layer formed on the surface is not continuous (incomplete coverage or mixture of oxide and metallic states). The peaks of higher binding energies are assigned to various forms of oxides. Before the sputtering process the $\mathrm{Ti} 2 p_{3 / 2}$ peak at $460 \mathrm{eV}$, and Mo $3 d_{5 / 2}$ at $230.42 \mathrm{eV}$ indicate presence of nonstoichiometric $\mathrm{TiO}_{2}$ and $\mathrm{MoO}_{2}$ oxides. Other forms of oxides such as stoichiometric $\mathrm{TiO}_{2}$ and $\mathrm{MoO}_{2}$ ( $\mathrm{Ti} 2 p_{3 / 2}$ at $458.24 \mathrm{eV}$, and Mo $3 d_{5 / 2}$ at $229.76 \mathrm{eV}$ ) or assigned to $\mathrm{MoO}_{3}$ peak at $232.73 \mathrm{eV}$ are also present. After the sputtering process the tendency for both elements is similar - the amount of nonstoichiometric $\mathrm{TiO}_{2}$ and $\mathrm{MoO}_{2}$ have been reduced, and some new intermediate oxides appeared (Fig. 1). This indicates that the oxidation process was in some way gradual.
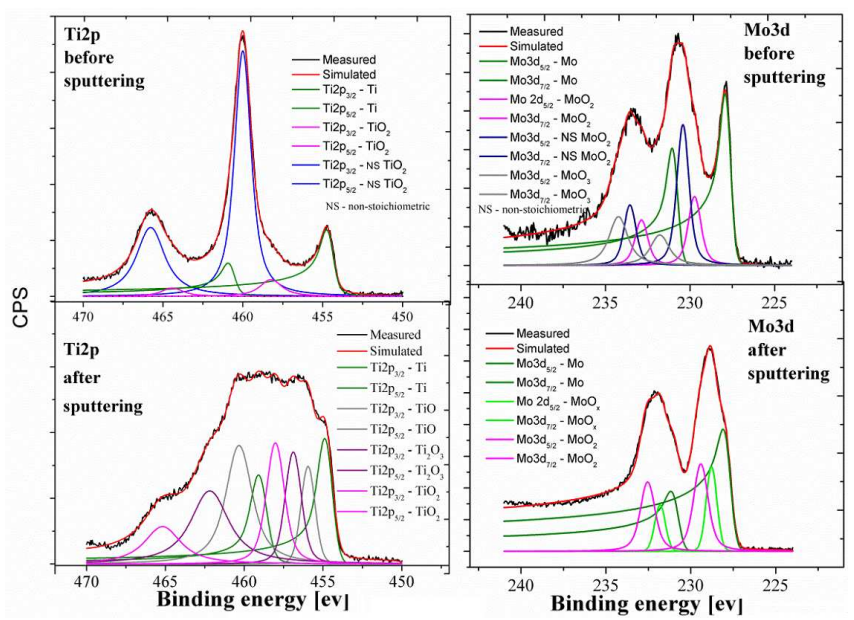

Fig. 1. High-resolution XPS spectra of the Ti2p and Mo3d levels obtained before and after the sputtering process. The raw data spectra (black) are fitted with several components assigned to particular chemical states as marked in the legend.

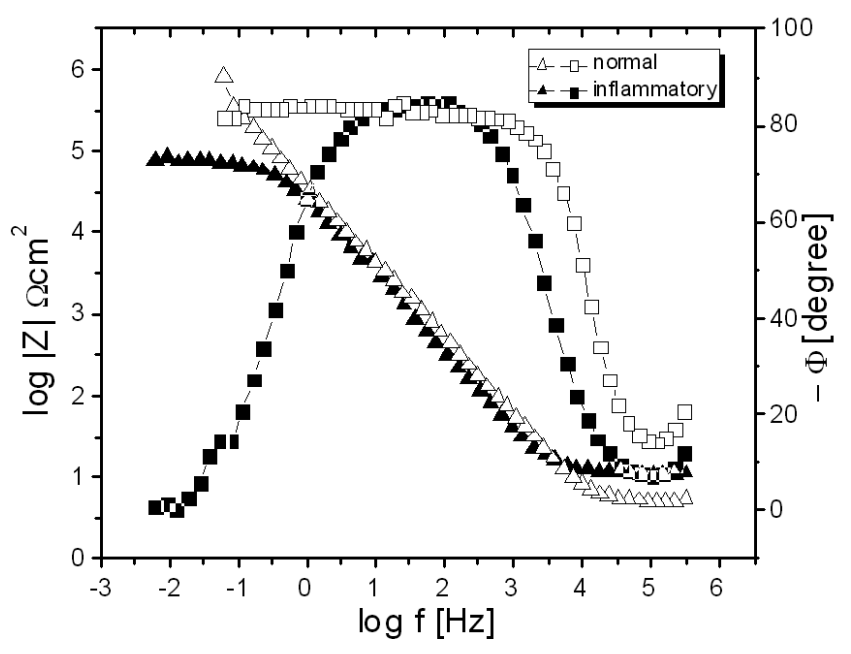

Fig. 2. Bode plots for Ti-15Mo implant alloy at $E_{O C}$ for normal and inflammatory conditions.

All impedance spectra registered towards corrosion behavior and semi-conducting properties of the $\mathrm{Ti}-15 \mathrm{Mo}$ alloy were approximated using the modified Randle's cell [9] which represents the physical model of the $\mathrm{Ti}-$ $15 \mathrm{Mo} \mid \mathrm{TiO}_{2}$ film|PSS system. The constant phase element (CPE) was used instead of a capacitor. The results of EIS measurements conducted at $\mathrm{E}_{O C}$ for the neutral and inflammatory state, were presented in Bode diagrams (Fig. 2). Bode-phase plots show one time constant characteristic for the oxide layer presence on the metallic substrate. The value of $\log |Z|_{f=0.1 \mathrm{~Hz}}$ for the neutral and inflammatory state is $5.51 \pm 0.49$ and $4.84 \pm 0.49 \Omega \mathrm{cm}^{2}$, respectively. It suggests that presence of additional chloride ions and increasing temperature of the solution increase the probability of occurrence the pitting corrosion at inflammatory state. Mott-Schottky (M-S) analysis of capacitance parameter determined in EIS tests allowed to determine the type of semi-conductivity and carrier concentration in the oxide layer. The donor density, $N_{D}$, and flat band potential, $V_{f b}$, were calculated from the Eq. (1) [10]:

$$
\frac{1}{C^{2}}=\frac{2}{\varepsilon_{\mathrm{TiO}_{2}} \varepsilon_{0} A^{2} e N_{D}}\left(V-V_{f b}-\frac{k_{\mathrm{B}} T}{e}\right),
$$

where: $C$ is the capacitance, $\varepsilon_{\mathrm{TiO}_{2}}$ is the dielectric constant of $\mathrm{TiO}_{2}, \varepsilon_{0}=8.85 \times 10^{-14} \mathrm{~F} / \mathrm{cm}$ is permittivity of free space, $e$ is the elementary charge $\left(1.6 \times 10^{-19} \mathrm{C}\right)$, $A$ is the tested surface area, $V$ is the voltage of the interface, $k_{\mathrm{B}}$ is the Boltzmann constant, and $T$ is a temperature. The M-S plot for neutral conditions shows a flat area at potential of $0.3-4.5 \mathrm{~V}$ indicating that investigated material behaves like insulator (Fig. 3). Whereas the positive slope of the curve $1 / C^{2}=f(E)$ in Fig. 3 points the n-type semi-conductivity with carrier concentration of $N_{D}=5.84 \times 10^{18} \mathrm{~cm}^{-3}$ and $V_{f b}=-4.97$ for the $\mathrm{Ti}-15 \mathrm{Mo}$ alloy exposed to inflammatory conditions.

Anodic polarization measurements indicate slightly better corrosion resistance of the $\mathrm{Ti}-15 \mathrm{Mo}$ alloy at in- 


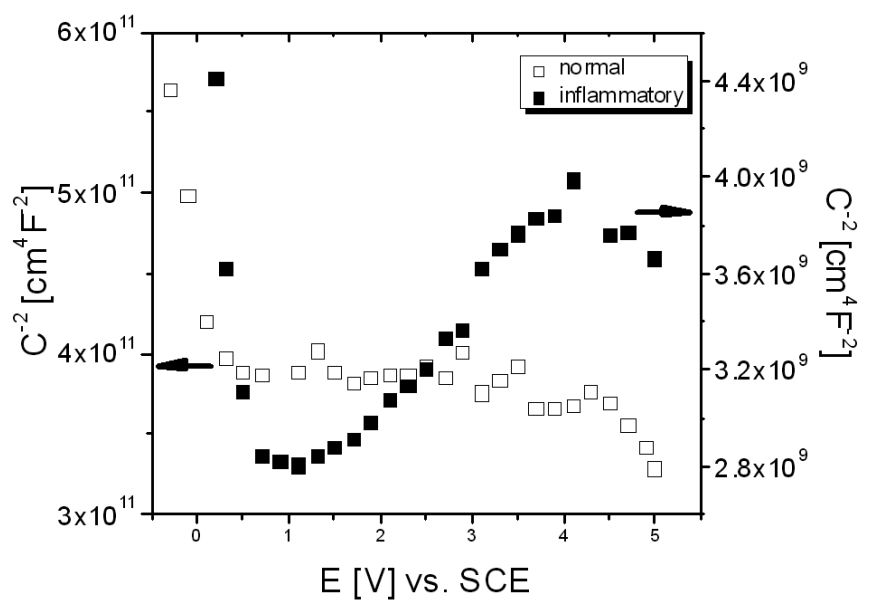

Fig. 3. Mott-Schottky plots for Ti-15Mo at normal and inflammatory conditions.

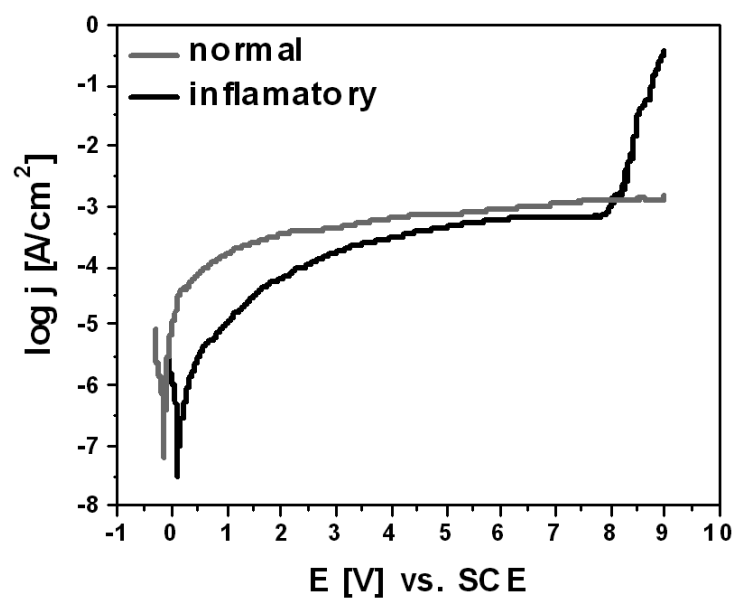

Fig. 4. Anodic potentiodynamic curve for $\mathrm{Ti}-15 \mathrm{Mo}$ alloy in PSS.

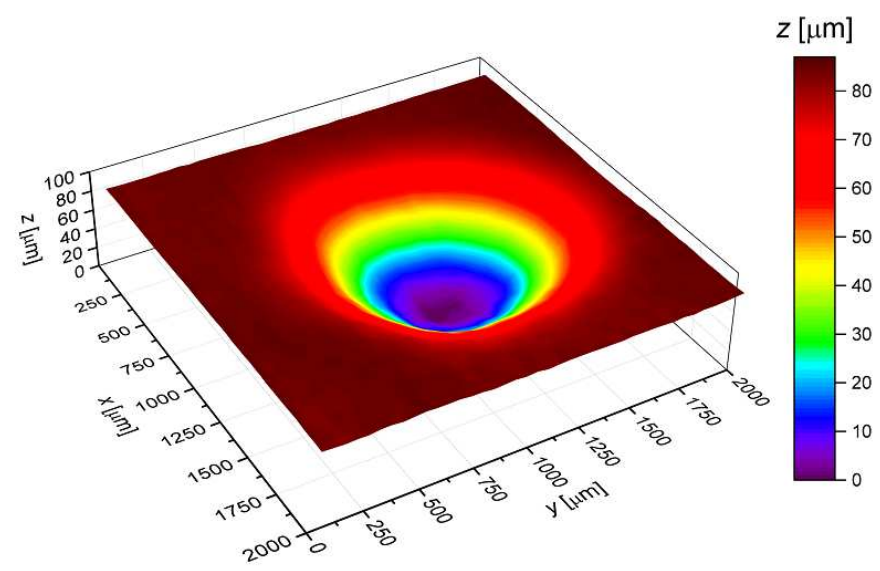

Fig. 5. Topography of corrosion pit on Ti-15Mo surface obtained by the SKP method. flammatory conditions (Fig. 4). It is evidenced by the lower current density for inflammation state. However significant increase in current density at potential of $8 \mathrm{~V}$ indicates that brake-down of protection oxide layer has occurred and pitting corrosion had started. SKP measurements allowed to determine the corrosion pit depth of $87 \mu \mathrm{m}$. This method also revealed that the corrosion pit has a shape of hopper with the diameter of $2000 \mu \mathrm{m}$ and $500 \mu \mathrm{m}$ at the hopper top and bottom, respectively (Fig. 5). Measurements of contact potential difference indicate that the bottom of corrosion pit has lower corrosion resistance than the surrounding surface.

\section{Conclusions}

Electrochemical behavior of oxide layer present on the Ti-15Mo implant alloy is strongly dependent on the occurrence of inflammation in human body. At normal conditions oxide layer behaves as an insulator whereas at inflammatory conditions it shows n-type semi-conductivity with carrier concentration $N_{D}=5.84 \times 10^{18} \mathrm{~cm}^{-3}$. This behavior is caused by addition of $\mathrm{H}_{2} \mathrm{O}_{2}$ into solution and increase in temperature and number of chloride ions. It could be the reason that more defected oxides are formed on the examined alloy surface which affect the semiconducting properties and also influence decreasing of corrosion resistance of $\mathrm{Ti}-15 \mathrm{Mo}$ in biological milieu at inflammatory state.

\section{References}

[1] J. Lelątko, T. Goryczka, T. Wierzchoń, M. Ossowski, B. Łosiewicz, E. Rówinski, H. Morawiec, Solid State Phenom. 163, 127 (2010).

[2] A. Smołka, K. Rodak, G. Dercz, K. Dudek, B. Łosiewicz, Acta Phys. Pol. A 125, 932 (2014).

[3] M. Szklarska, G. Dercz, W. Simka, B. Łosiewicz, Surf. Interface Anal. 46, 698 (2014).

[4] W. Simka, A. Krząkała, D.M. Korotin, I.S. Zhidkov, E.Z. Kurmaev, S.O. Cholakh, K. Kuna, G. Dercz, J. Michalska, K. Suchanek, T. Gorewoda, Electrochim. Acta 96, 180 (2013).

[5] M. Freitag, B. Łosiewicz, T. Goryczka, J. Lelątko, Solid State Phenom. 183, 57 (2012).

[6] P. Handzlik, K. Fitzner, Trans. Nonferrous Met. Soc. China 23, 866 (2013).

[7] E. Brooks, M. Tobias, K. Krautsak, M. Ehrensberg, J. Biomed. Mater. Res. B 102, 1445 (2014).

[8] I.M. Pohrelyuk, V.M. Fedirko, O.V. Tkachuk, R.V. Proskurnyak, Corros. Sci. 66, 392 (2013).

[9] A.S. Bondarenko, G.A. Ragoisha, J. Solid State Electrochem. 9, 845 (2005).

[10] M. Szklarska, G. Dercz, J. Rak, W. Simka, B. Łosiewicz, Archiv. Metall. Mater. 4, 2687 (2015). 